\title{
PRÁTICAS DE EDUCAÇÃO AMBIENTAL EM UMA ESCOLA DE CAMPO
}

\author{
Eliane Marili Uhde ${ }^{1}$ \\ Leonir Terezinha Uhde ${ }^{2}$ \\ Vidica Bianchi ${ }^{3}$ \\ Sandra Beatriz Vicenci Fernandes ${ }^{4}$
}

\begin{abstract}
Resumo: Este trabalho teve como objetivo relatar experiências de Educação Ambiental em uma escola de campo da rede estadual, dinamizadas por meio da práxis que vincula o cotidiano das pessoas às questões socioambientais e, dessa forma, fortalece os vínculos com a comunidade escolar. Além disso, propõe-se a refletir sobre o alcance de práticas convencionais comumente adotadas na Educação Ambiental (EA). Assim, apresentam-se práticas de EA desenvolvidas durante o período escolar que mobilizaram os estudantes, os professores e a comunidade local. Conclui-se que, por se tratar de uma escola de campo, a Educação Ambiental deve ter nexo com a vida no campo, envolvendo a comunidade em sentido amplo e assegurando o vínculo com este contexto.
\end{abstract}

Palavras-chave: Ações Multidisciplinares; Conscientização; Meio Ambiente.

Abstract: The present study aimed to report experiences of environmental education in a state country school, taught through praxis connecting people's daily life to social and environmental issues, and thus, fortifying the bonds with the school community. Moreover, this study seeks to reflect on the coverage of conventional practices commonly adopted in environmental education (EE). Therefore it is presented the $E E$ practices developed during a school term that mobilized students, teachers, and the local community. In conclusion, due to being a country school, environmental education needs to have a connection with country life embracing the community in its broader sense and securing the connection with its context.

Keywords: Multidisciplinary Actions; Awareness; Environment.

${ }^{1}$ Unijuí - Universidade Regional do Noroeste do Estado do Rio Grande do Sul. E-mail: elianeuhde@hotmail.com. Link para o Lattes: http://lattes.cnpq.br/6844769748349458

2 Unijuí - Universidade Regional do Noroeste do Estado do Rio Grande do Sul. E-mail: uhde@unijui.edu.br.

Link para o Lattes: http://lattes.cnpq.br/7835678504674897

3 Unijuí - Universidade Regional do Noroeste do Estado do Rio Grande do Sul. E-mail: vidica.bianchi@unijui.edu.br. Link para o Lattes: http://lattes.cnpq.br/3979701002447139

4 Unijuí - Universidade Regional do Noroeste do Estado do Rio Grande do Sul. E-mail: sandravf@unijui.edu.br.

Link para o Lattes: http://lattes.cnpq.br/4291153917896209

Revbea, São Paulo, v.16, № 1: 114-129, 2021. 


\section{Introdução}

Muitos debates têm ocorrido nos últimos anos acerca da conscientização dos sujeitos por meio da Educação Ambiental (EA) - formal e informal. No espaço formal, considera-se a escola o melhor meio para o despertar da consciência ecológica, em que professores se tornam mediadores do processo de "alfabetização ecológica", despertando valores como cooperação, igualdade de direitos, autonomia, democracia e a participação em atividades e vivências na escola e no entorno, tornando-o agente ativo deste processo significativo.

Uma proposta de Educação para a sustentabilidade justifica-se pela percepção sobre o incipiente processo de reflexão acerca das práticas existentes e das múltiplas possibilidades de, ao pensar a realidade de modo complexo, defini-la como uma nova racionalidade e um espaço em que se articulam natureza, técnica e cultura. Partir da complexidade ambiental permite uma estimulante oportunidade para se compreender a gestão de novos atores sociais, que se mobilizam para refletir sobre a apropriação da natureza, e para um processo educativo articulado e compromissado com a sustentabilidade e a participação, apoiado numa lógica que privilegia o diálogo e a interdependência de diferentes áreas de saber (MORIN, 2000, 2002, 2003; LEFF, 2012).

A EA, de acordo com Boff (1999), é um campo interdisciplinar do conhecimento que estuda a relação sociedade e natureza, tendo como pano de fundo a problemática ambiental derivada de paradigmas construídos historicamente e que favoreceram uma relação degeneradora, baseada no domínio e na exploração. O enfrentamento da problemática ambiental é constituído por diversas variáveis, resultando na incorporação de novos valores que dão sentido aos processos emancipatórios e redefinem a qualidade de vida das pessoas e o significado da existência humana.

Leff (2001) discorre sobre a impossibilidade de resolver os crescentes e complexos problemas ambientais e reverter causas sem que ocorra uma mudança radical nos sistemas de conhecimento, nos valores e nos comportamentos gerados pela dinâmica de racionalidade existente, fundada no aspecto econômico do desenvolvimento. A defesa do meio ambiente emerge como movimento de resistência ao pensamento capitalista moderno baseado numa racionalidade econômica. A mais grave consequência e prejuízo dessa racionalidade irracional é a degradação social e ambiental (TRISTÃO, 2004). Nesse contexto, ganha sentido o papel da EA.

A formalização da Política Nacional de Educação Ambiental - pela Lei ํo 9.795/1999, artigo $1^{\circ}$ - descreve que a EA se constitui pelos processos por meio dos quais,

o indivíduo e a coletividade constroem valores sociais, conhecimentos, habilidades, atitudes e competências voltadas para a conservação do meio ambiente, bem de uso comum do povo, essencial à sadia qualidade de vida e sua sustentabilidade (BRASIL, 1999).

Revbea, São Paulo, v.16, № 1: 114-129, 2021.

revista brasileira educação ambiental 
A abordagem interdisciplinar e a transdisciplinar da Educação Ambiental suscitam uma compreensão da realidade de modo complexo, pois quanto mais descobrimos mais nos damos conta da nossa limitação. Na estrutura conceitual de currículo, por disciplinas, não se sabe muito bem onde encaixar a Educação Ambiental. Sua natureza anti-disciplinar provoca uma inserção por meio de projetos e/ou atividades extracurriculares (TRISTÃO, 2004, p.48).

A EA visa a desenvolver capacidades para analisar critérios e ações de forma justa, proporcionando um senso crítico, ético e moral em relação ao mundo e almejando uma melhor qualidade de vida (JACOBI, 2005). Desse modo, a escola torna-se o espaço educativo, indispensável para a formação tanto social quanto ambiental.

Trabalhos em EA permitem questionar valores e premissas que norteiam as interações sociais prevalentes, implicando mudanças na forma de pensar e de transformar o conhecimento e as práticas educativas. A realidade atual exige uma reflexão cada vez menos linear, e isto produz-se na interrelação dos saberes e das práticas coletivas que criam identidades e valores comuns e ações solidárias diante da reapropriação da natureza, numa perspectiva que privilegia o diálogo que os conecta (LEFF, 2001). Tais saberes devem, necessariamente, perpassar diversas áreas do conhecimento, de forma que os envolvidos no processo educacional, formal ou não formal, venham a apropriar-se deste conhecimento, mudando o comportamento com atitudes conscientes e ações coletivas e efetivas. Trata-se de um aprendizado social baseado no diálogo e na interação em constante processo de recriação e reinterpretação de informações, conceitos e significados, que podem se originar do aprendizado em sala de aula ou da experiência pessoal do aluno.

A preocupação com o desenvolvimento sustentável representa a possibilidade de garantir mudanças sociopolíticas que não comprometam os sistemas ecológicos e sociais que sustentam a vida. Dentre os 17 objetivos do Desenvolvimento Sustentável para 2030, a educação está contemplada no objetivo 4: "Assegurar a educação inclusiva e equitativa e de qualidade, e promover oportunidades de conhecimentos e habilidades imprescindíveis à promoção do desenvolvimento sustentável"' (ONU, 2015).

Neste contexto, algumas questões são colocadas: Como as questões socioambientais são e devem ser abordadas nos diferentes níveis de aprendizagem? Como as atividades interdisciplinares entre docentes e discentes poderão contribuir para abordar as questões socioambientais? Quais são os pressupostos básicos da aprendizagem ao longo da vida para todos? Até 2030 todos os alunos terão acesso e vivências de uma educação socioambiental para sociedades sustentáveis? Quais são as proposições de conteúdos básicos que deverão ser trabalhados nos diferentes níveis? Por que dialogar sobre educação para o desenvolvimento sustentável ou para sociedades sustentáveis?

Revbea, São Paulo, v.16, № 1: 114-129, 2021. 
A escola é o espaço onde aprender é compreender, é transformar e agir; local de se estabelecer relações significativas entre o novo e o que já se sabe, levando em conta o afetivo e o social. Por meio da EA a escola, preocupada com a educação para a sustentabilidade, tem por missão preparar o aluno para o exercício da cidadania, mediante a participação individual e coletiva, considerando os processos socioeconômicos, políticos, culturais e ambientais.

Educadores e comunidade escolar devem ocupar-se em adotar medidas e posturas na escola, em casa e na sociedade, que os levem a interações construtivas, justas e ambientalmente sustentáveis, desenvolvendo novos valores éticos, culturais, sociais e econômicos para uma mudança de comportamentos, sentimentos e atitudes, reorientando novos estilos de consumo e relações com a verdadeira felicidade, conforme asseveram Baroldi e Lopes (2017).

Este trabalho teve como objetivo relatar experiências de Educação Ambiental em uma escola de campo da rede estadual, dinamizadas por meio da práxis que vincula o cotidiano das pessoas às questões socioambientais $e$, dessa forma, fortalece os vínculos com a comunidade escolar. Além disso, propõe-se a refletir sobre 0 alcance de práticas convencionais comumente adotadas na EA.

\section{Fundamentação Teórica}

\section{Antecedentes da Educação Ambiental}

A origem da Educação Ambiental situa-se nos anos 70 do século 20, com a emergência de uma percepção mais clara sobre a relevância da problemática ambiental. A evolução da consciência global sobre as problemáticas socioambientais ocorreu em diferentes etapas e com características diferenciadas. Alguns dos principais fatos que corroboraram e que permitiram avanços na EA são apresentados na Tabela 1 (próxima página).

Em relação aos objetivos globais da EA, um marco importante foi a primeira Conferência Intergovernamental de Educação Ambiental organizada pela Unesco e pelo Programa das Nações Unidas para o Meio Ambiente (PNUMA) em 1977 em Tbilisi, Geórgia. Desse encontro emergiram as definições, os objetivos, os princípios e as estratégias para a EA que persistem como desafios: promover uma clara consciência e preocupação sobre a interdependência das esferas econômica, social, política e ecológica em áreas urbanas e rurais; prover a cada pessoa oportunidades para adquirir os conhecimentos, valores, atitudes, compromissos e habilidades necessárias para proteger e melhorar o ambiente e para alcançar os objetivos do desenvolvimento sustentável; criar nos indivíduos, nos grupos e na sociedade inteira, novos padrões de comportamento e responsabilidades éticas para com o ambiente e, por fim, despertar no aluno a consciência de preservação e cidadania (BARBIERI; SILVA, 2011). 
Tabela 1: Marcos significativos da evolução da consciência global sobre o meio ambiente e a consolidação de políticas de Educação Ambiental.

\begin{tabular}{|c|c|}
\hline Data & $\begin{array}{l}\text { Eventos e fatos significativos sobre a evolução da consciência global, o } \\
\text { meio ambiente e a consolidação de políticas sobre a Educação Ambiental }\end{array}$ \\
\hline 1961 & $\begin{array}{l}\text { Criação da Fundação Vida Silvestre Mundial (World Wildlife Fund, WWF), } \\
\text { depois chamada de Fundo Mundial para a Natureza (World Wild Fund). }\end{array}$ \\
\hline 1968 & $\begin{array}{l}\text { Cria-se o Conselho para a Educação Ambiental (Council for Environmental } \\
\text { Education) no Reino Unido. }\end{array}$ \\
\hline 1970 & Ano Europeu da Conservação da natureza. \\
\hline 1971 & $\begin{array}{l}\text { Fundação do Greenpeace, uma organização com intervenções diretas nos } \\
\text { problemas ambientais. }\end{array}$ \\
\hline 1972 & $\begin{array}{l}\text { Publicação do livro "Os limites do Crescimento" pelo Clube de Roma, } \\
\text { coordenado pelo economista Meadows. } \\
\text { Realiza-se em Estocolmo (Suécia) a primeira Cúpula da Terra, Conferência das } \\
\text { Nações Unidas sobre o Meio Ambiente Humano. }\end{array}$ \\
\hline 1973 & $\begin{array}{l}\text { Nasce o Programa das Nações Unidas para o Meio Ambiente Humano } \\
\text { (PNUMA) como um dos resultados da Conferência de Estocolmo de } 1972 .\end{array}$ \\
\hline 1975 & $\begin{array}{l}\text { Criação do Programa Internacional de Educação Ambiental (PIEA) da } \\
\text { Organização Educacional, Científica e Cultural das Nações Unidas (Unesco) e } \\
\text { o PNUMA. } \\
\text { Realização do Seminário Internacional de Educação Ambiental, em Belgrado. }\end{array}$ \\
\hline 1976 & $\begin{array}{l}\text { Reunião de especialistas em Educação Ambiental da América Latina e do } \\
\text { Caribe em Bogotá (Colômbia). }\end{array}$ \\
\hline 1977 & $\begin{array}{l}\text { Realização, em Tbilisi (Georgia), da Primeira Conferência Intergovernamental } \\
\text { de Educação Ambiental. }\end{array}$ \\
\hline 1979 & $\begin{array}{l}\text { Emergência do primeiro partido político com reivindicações ecológicas em sua } \\
\text { plataforma política: o Partido Verde Alemão. }\end{array}$ \\
\hline 1980 & $\begin{array}{l}\text { Publicação do documento: "Estratégia Mundial para a Conservação da } \\
\text { Natureza", do qual participaram a União Internacional para a Conservação da } \\
\text { Natureza (UICN), WWF e PNUMA. }\end{array}$ \\
\hline 1980 & $\begin{array}{l}\text { Publicação do documento: "Estratégia Mundial para a Conservação da } \\
\text { Natureza", do qual participaram a União Internacional para a Conservação da } \\
\text { Natureza (UICN), WWF e PNUMA. }\end{array}$ \\
\hline 1987 & cional de Educação Ambiental em Moscou. \\
\hline 1992 & $\begin{array}{l}\text { Realização da segunda Cúpula da Terra, Conferência Mundial sobre Ambiente } \\
\text { e Desenvolvimento (CNUMAD) no Rio de Janeiro, Brasil, quando se aprovou a } \\
\text { Agenda } 21 \text {. Um dos capítulos foi dedicado à Educação Ambiental, além da } \\
\text { proposição do Tratado de Educação Ambiental para Sociedades Sustentáveis } \\
\text { e responsabilidade Global, elaborado pela sociedade civil planetária durante a } \\
\text { Conferência das Nações Unidas sobre Meio Ambiente e Desenvolvimento (Rio- } \\
\text { 92). }\end{array}$ \\
\hline $1999 / 2002$ & $\begin{array}{l}\text { Aprovação da Lei no 9.795, de } 27.4 .1999 \text { e do seu regulamento, o Decreto no } \\
4.281 \text {, de 25.6.20025, estabelecendo a Política Nacional de Educação } \\
\text { Ambiental (PNEA). }\end{array}$ \\
\hline 1992 & $\begin{array}{l}\text { Eleição da Década da Educação para o Desenvolvimento Sustentável (2005- } \\
\text { 2014) - Nações Unidas e Unesco. }\end{array}$ \\
\hline 2000 & $\begin{array}{l}\text { Proposição, pelas Nações Unidas, dos Objetivos do Desenvolvimento do } \\
\text { Milênio (ODM), para promover esforços de sua inserção nas agendas } \\
\text { internacionais, nacionais e locais quanto ao meio ambiente e direitos humanos. }\end{array}$ \\
\hline 2015 & $\begin{array}{l}\text { Proposição da Agenda } 2030 \text { - Objetivos de Desenvolvimento Sustentável } \\
\text { (ODS). Trata-se de } 17 \text { objetivos globais e } 169 \text { metas para alcançar o } \\
\text { Desenvolvimento sustentável, enfatizando dimensões econômica, social, } \\
\text { ambiental, cultural e política de forma equilibrada e integrada. Sua efetivação } \\
\text { deverá ocorrer no período correspondente a } 2016-2030 \text {. }\end{array}$ \\
\hline
\end{tabular}

Fonte: Elaboração dos autores.

Revbea, São Paulo, v.16, № 1: 114-129, 2021. 
Os objetivos da EA postulam, portanto, o conhecimento da dinâmica que incorpora o meio ambiente e pretende uma forte atuação dos indivíduos, produto da aquisição de condutas responsáveis, éticas e comprometidas. Uma das questões colocadas nessa época estava relacionada às modalidades de promoção de conhecimento e consciência em relação ao ambiente, considerando o fato de a Educação Ambiental não estar concebida como uma temática para o ambiente nas escolas.

Neste sentido, acredita-se que os conteúdos escolares devem integrar a educação como instrumento para criar e promover valores, ideias, sensibilidades e atitudes favoráveis à preservação do meio ambiente considerando sua carga ideológica -, que tantas vezes a escola descarta por pretender se manter "neutra" nestas questões. Em síntese acerca deste período de emergência da EA, Lima (2009, p. 151) sumariza,

do ponto de vista internacional, as grandes conferências e os encontros das Nações Unidas a partir de 1970 e os debates internacionais desencadeados a partir do Relatório Meadows não só promoveram a publicização da questão ambiental como forneceram uma base argumentativa que alimentava a nascente consciência ambiental. Embora tivesse aspectos problemáticos, o Relatório Meadows desconstruía o mito econômico que apostava num crescimento econômico infinito a partir de uma base de recursos naturais, cada vez mais, percebida como finita e vulnerável à expansão capitalista.

Em 1992, a Conferência das Nações Unidas sobre o Meio Ambiente e Desenvolvimento (CNUMAD/Unced), realizada no Rio de Janeiro, também denominada de RIO-92, ECO-92 ou Cúpula da Terra, promoveu discussões que culminaram em novas concepções sobre as questões ambientais. Dentro desse contexto, a admissão da necessidade de se considerar a dimensão social conduziu ao uso da designação socioambiental, que, além de destacar a sociedade como elemento constituinte da questão ambiental, manifesta a busca de conceitos que auxiliem no processo de compreensão dessa realidade complexa (RODRIGUES; COLESANTI, 2008).

Há que se considerar que os objetivos do desenvolvimento sustentável exigem uma mudança nos valores que orientam o comportamento dos agentes econômicos e da sociedade em seu conjunto, além da transformação do conhecimento em estímulo à inovação de tecnologias para resolver os problemas ambientais. A sensibilização da sociedade, a incorporação do saber ambiental emergente no sistema educacional e a formação de recursos humanos de alto nível, foram considerados processos fundamentais para orientar e instrumentar as políticas ambientais (LEFF, 2002).

De acordo com Carvalho (2001) e Jacobi (2004), o mais desafiador é evitar cair na simplificação da EA e superar uma relação pouco harmoniosa entre os indivíduos e o meio ambiente por meio de práticas localizadas e 
pontuais, muitas vezes distantes da realidade social de cada aluno. Cabe sempre enfatizar a historicidade da concepção de natureza, o que possibilita a construção de uma visão mais abrangente e complexa, como são as questões ambientais, que promova ações em busca de alternativas e soluções. Há necessidade de se visar a uma transformação mais profunda no conteúdo, no processo e no alcance da educação em todos os níveis. Trata-se, como propõem Capra et al. (2006), da alfabetização ecológica, fundamentada em conhecimentos básicos de ecologia, de ecologia humana e dos conceitos de sustentabilidade, bem como dos meios necessários para a solução dos problemas.

A educação para uma vida sustentável é uma pedagogia que facilita esse entendimento por ensinar os princípios básicos da ecologia e, com eles, um profundo respeito pela natureza viva, por meio de uma abordagem multidisciplinar baseada na experiência e na participação. A compreensão sistêmica da vida, que hoje está assumindo a vanguarda da ciência, baseia-se no entendimento de três fenômenos essenciais: o padrão básico de organização da vida é o da rede ou teia; a matéria percorre ciclicamente a teia da vida; todos os ciclos ecológicos são sustentados pelo fluxo constante de energia proveniente do sol. Esses três fenômenos básicos - a teia da vida, os ciclos da natureza e o fluxo de energia - são os pilares que estruturam as vivências e experiências diretas com o mundo natural (CAPRA et al., 2006).

Este recorte estimula tanto o entendimento intelectual da ecologia quanto cria vínculos emocionais com a natureza. Por isso, ela tem muito mais probabilidade de fazer com que os educandos se tornem cidadãos responsáveis e realmente preocupados com a sustentabilidade da vida, e que sejam capazes de desenvolver uma paixão pela aplicação dos seus conhecimentos ecológicos para a reformulação das nossas tecnologias e instituições sociais, de maneira a preencher a lacuna existente entre a prática humana e os sistemas da natureza ecologicamente sustentáveis.

A EA deve ser um processo contínuo e permanente, iniciando em âmbito pré-escolar e estendendo-se por todas as etapas da educação formal ou informal (GUIMARÃES, 2000, 2004). Este trabalho ocorre pela mediação dos professores, visando à conscientização e à transformação da consciência ambiental nos educandos por meio do despertar de valores, como a cooperação, a igualdade de direitos, a autonomia, a democracia e a participação destes nas vivências em sala de aula, oficinas afins, espaço escolar, pátio, vivências familiares, fenômenos que ocorrem a sua volta e conceitos científicos.

De acordo com Loureiro (2003), pode-se estabelecer, para efeito de análise e compreensão didática, dois eixos para o discurso da EA como vetor de transformação: um, conservador, em que o processo educativo promove mudanças superficiais para garantir o status quo e a alteração de certas atitudes e comportamentos, sem que isso signifique incompatibilidade com o modelo de sociedade contemporânea em que vivemos; já o outro eixo, 
considerado revolucionário e emancipatório, consiste efetivamente em uma perspectiva de Educação transformadora,

em que a dialética forma e o conteúdo se realiza plenamente, de tal maneira que as alterações da atividade humana implicam em mudanças radicais individuais e coletivas, locais e globais, estruturais e conjunturais, econômicas e político-sociais, psicológicas e culturais; em que o sentido de revolucionar se concretiza como sendo a transformação integral do ser e das condições materiais e objetivas de existência (LOUREIRO, 2003, p. 39).

Na perspectiva de Loureiro (2003), a EA em si não é garantia de transformação efetiva, mas, ao contrário, pode reproduzir uma visão conservadora de educação e sociedade, que pode ser ilustrada nos recorrentes projetos de coleta seletiva de lixo. Considerando seu alinhamento a uma visão conservadora, parte-se de um pressuposto equivocado: o de que o lixo sempre é o problema principal a ser enfrentado, e, em grande medida, acaba-se, intencionalmente ou não, reproduzindo um modelo que não enfrenta a relação produção-consumo-cultura. Nesse contexto, o lixo não é visto nem enfrentado como problema em sua complexidade e totalidade, restringindo-se a um fator de reciclagem de recursos e de mudança comportamental, favorecendo mais certos setores sociais do que o conjunto da sociedade.

Nunca é demais ressaltar, contudo, que a ação transformadora da educação possui limites, ou seja, não é suficiente em si para realizar uma práxis educativa cidadã, participativa e revolucionária, se isso não se relacionar diretamente com outras esferas da vida. Como pondera Konder (1992), a práxis é a atividade concreta pela qual os sujeitos se afirmam no mundo. Desta forma, modificam a realidade objetiva e por ela são modificados, não de modo espontâneo, mecânico e repetitivo, mas reflexivo, pelo autoquestionamento, remetendo a teoria à prática. A práxis e, por extensão a EA revolucionária, portanto, é a atividade que precisa de um sujeito livre e consciente bem como da teoria.

\section{Os Caminhos da Pesquisa}

\section{Escola no campo}

A educação do campo compreende a educação básica em todas as suas modalidades de ensino. As populações do meio rural têm o direito garantido pela lei a um ensino de qualidade contextualizado, respeitando as características dos diversos sujeitos que residem nestes territórios. Aprovada

pela Resolução no 1 de 3 de abril de 2002, a Educação do Campo é conceituada, no parágrafo único da lei, da seguinte forma: 
a identidade da escola do campo é definida pela sua vinculação às questões inerentes à sua realidade, ancorandose na temporalidade e saberes próprios dos estudantes, na memória coletiva que sinaliza futuros, na rede de ciência e tecnologia disponível na sociedade e nos movimentos sociais em defesa de projetos que associem as soluções exigidas por essas questões à qualidade social da vida coletiva no país (BRASIL, 2002, p. 1).

Além da necessidade de metodologias de ensino que tenham uma proposta diferenciada no sentido de articulação dos conteúdos com as realidades vivenciadas pelos alunos do campo, as escolas também precisam ter uma estrutura de atendimento de qualidade.

Este trabalho trata-se de uma pesquisa qualitativa e insere-se na modalidade de estudo de caso (LÜDKE; ANDRÉ, 1986). Segundo Zanelli (2002, p. 83), o principal objetivo da pesquisa qualitativa "é buscar entender o que as pessoas apreendem ao perceberem o que acontece em seus mundos". Os procedimentos metodológicos para obtenção de informações para a compreensão da realidade estudada, compreendem pesquisa bibliográfica, documental, observação direta e participação nas ações realizadas na escola.

\section{Contexto e sujeitos da pesquisa}

A pesquisa foi desenvolvida em uma escola de campo, a qual está localizada a 6 quilômetros da cidade e recebe estudantes da região rural e urbana (alguns alunos em situação de vulnerabilidade social) oriundos de um bairro pobre do município, filhos de agricultores e funcionários da produção leiteira. A escola conta com a gestão do diretor, coordenação, bibliotecária, secretário, três funcionárias (sendo uma cozinheira e duas faxineiras), cinco professores nos anos iniciais e dez do sexto ao nono anos, atendendo os anos iniciais no turno da manhã e, à tarde, os anos finais. Todos os professores deslocam-se diariamente da cidade até a escola com uso de transporte coletivo próprio dos professores e funcionários. A organização da escola e do ensino baseia-se no Regimento Escolar, instrumento formal e legal, resultado normativo do que se definiu no Projeto Político Pedagógico (PPP). Trata-se de um documento elaborado coletivamente, envolvendo toda a comunidade escolar.

A escola oferece dois níveis de Ensino: a Educação Infantil, abrangendo a pré-escola, e o Ensino Fundamental. O Calendário Escolar é construído coletivamente pela comunidade escolar (professores, funcionários, alunos e pais e/ou responsáveis) e prevê, no mínimo, 200 dias letivo e 800 horas/aulas para o Ensino Fundamental. A educação básica está organizada em séries anuais e oferece, a partir de 2019, educação fundamental apenas. Em 2019 não houve matrículas para a pré-escola; inclusive o PPP da escola está sendo alterado e não oferecerá mais educação infantil, somente o Ensino 
Fundamental.

O Ensino Fundamental compreende os anos iniciais (do $1^{\circ}$ ao $5^{\circ}$ ano) e anos finais (do 6ㅇ ao 9a ano). Os resultados avaliativos são feitos em forma de pareceres descritivos semestrais para o $1^{\circ}$ e $2^{\circ}$ anos, e para as demais turmas, do $3^{\circ}$ ao $9^{\circ}$ anos, são atribuídas notas de zero a cem, trimestralmente.

As práticas de EA, realizadas durante o período escolar, são: pedágio ecológico, uso de cisternas para captação de água, estufa (horta) e a recuperação da mata ciliar ao longo de um córrego com a intenção de mobilizar os estudantes, professores e a comunidade local para as problemáticas socioambientais.

\section{Resultados e Discussão}

As principais práticas de Educação Ambiental executadas pela escola constituem-se de:

a. Pedágio Ecológico - trata-se de uma prática que teve por objetivo contribuir com a conscientização da necessidade de restaurar o ambiente natural, introduzindo e cuidando de espécies arbóreas, as quais são distribuídas gratuitamente para pessoas que transitam no entorno da Escola (próximo à rodovia estadual RS 514), como caminhões, transportadores de leite, carretas que carregam soja e outros cereais, carros, tratores, motos e pessoas que transitam a pé. Essa ação integra uma prática da escola na Semana do Meio Ambiente, atualmente na sua $15^{\mathrm{a}}$ edição. Além da muda, agrega-se a ela uma mensagem: "Pensar sustentabilidade é pensar na família, no próximo e em você mesmo. Faça sua parte!!"; nessa edição acompanhada de uma lembrança: uma pequena barra de sabão feita por professores e alunos dos anos finais a partir do óleo de cozinha reaproveitado e de sua receita. Essa iniciativa teve uma repercussão muito positiva, tanto na comunidade local quanto junto aos viajantes que por ali transitam provenientes de inúmeras cidades da região. Neste sentido, concordamos com Mallman, Carniatto e Plein (2020) quando afirmam:

Diferentes iniciativas realizadas pela educação formal têm como objetivo o diálogo, a solidariedade e a participação social. Ações que podem fortalecer a construção de uma nova ética, que valorize não apenas a vida humana, mas todo o complexo ecossistema (p. 58).

b. Cisternas para captação de água - foi adotado o uso de cisternas para captação de água da chuva há muitos anos, com o objetivo de aproveitála para irrigar as plantas de duas estufas existentes na escola, bem como das flores do entorno, além de ser utilizada na limpeza da escola, resultando em economia e valorização da água de poço artesiano que a abastece (Figura 1). 

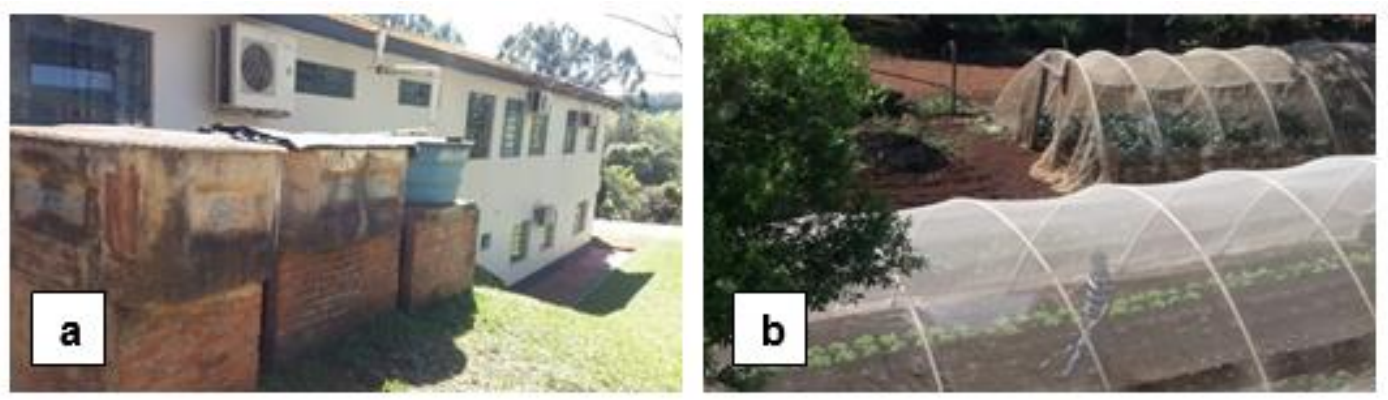

Figura 1: Práticas de Educação Ambiental em uma escola de campo: a. Cisternas para captação de água da chuva; b. Hortas em ambientes protegidos.

c. Hortas em ambiente protegido (estufas) - a prática do trabalho com horta, atualmente realizada em duas estufas, objetiva cumprir o papel de um laboratório de observações aos alunos (Figura 1). Esta prática tem estimulado o cultivo de espécies vegetais (comestíveis, aromáticas e condimentares), oportunizando o aprendizado em todas as etapas, compreendendo a organização de canteiros, as épocas de semeadura/plantio de cada espécie, a necessidade de irrigação e cuidados desenvolvendo o encantamento e apreço no trabalho com plantas. Embora a escola seja rural, a grande maioria dos alunos desconhece este tipo de atividade, uma vez que muitas famílias que residem no interior não possuem mais o hábito de cultivar hortas, por ser mais cômodo comprar no mercado. Este trabalho também proporciona um potencial resgate de vínculos afetivos e qualificação das relações sociais na coletividade.

Muitos trabalhos referem-se às hortas, em especial as escolares, como laboratórios vivos, ou verdadeiras salas de aula que podem integrar um currículo escolar que oportunize vivências para a sustentabilidade, além de promover o exercício da investigação e da pesquisa. A análise desta prática em diversos contextos (CARDONA; BARRETO, 2014; COSTA; SOUZA; PEREIRA, 2015; LUCENA; FIGUEROA; OLIVEIRA, 2015) elenca, como percepções, um ambiente que facilita a restauração psicológica, a saúde mental, a qualidade de vida, as interações socioambientais, a produtividade, a alimentação saudável e a economia. Os afetos experimentados foram frequentemente descritos com o sentido de identificar as hortas como ambientes restauradores e promotores de qualidade de vida. Tais espaços favorecem tanto a percepção da importância da biodiversidade quanto o reconhecimento de seu papel de tecnologia social, que contribui na economia familiar e na saúde da comunidade.

Pesquisas sobre atividades desenvolvidas em hortas, mostram que, após o manejo deste tipo de ambientes, os alunos desenvolveram atividades educativas que confirmam processo de aprendizagem. Segundo Pereira, Pereira e Pereira (2012), a horta permitiu o desenvolvimento de valores sociais e ambientais além de favorecer o desenvolvimento cognitivo dos alunos.

Silva (2009), entretanto, faz menção aos exemplos supracitados como práticas em que a relação entre educação e ambiente é reducionista, referindose às práxis muitas vezes meramente pontuais, como os temas lixo e horta. $\mathrm{O}$ 
que determinaria a superficialidade ou o reducionismo é a forma como são abordados. Para tanto, salienta-se a necessidade de se construir uma percepção mais ampla, aprofundada e crítica da EA.

d. Recuperação da mata ciliar ao longo de um córrego - esta ação teve como objetivo recuperar a nascente na propriedade da família de um aluno, tendo em vista que se localiza em um "potreiro" - área de pastagem nativa destinada à pecuária leiteira, atividade muito intensa nesta região à qual a escola está próxima. Ainda no tema água, merece reflexão a condição ambiental em torno do poço artesiano que abastece esta comunidade, também localizado nesta propriedade. Este poço encontra-se numa área plana da propriedade, próxima a um açude. No ano de 2019 foi iniciado um trabalho de melhorias em sua proteção, conforme estabelece a legislação ambiental e o tratamento com cloro, algo muito difícil de ser posto em prática em razão da resistência da comunidade local. A família comprometeu-se em realizar o isolamento para proteção da nascente e do córrego. A comunidade escolar fez o plantio de árvores nativas apropriadas para esta função e, após, acompanhou o seu desenvolvimento. Esta ação constitui um local que é visitado durante a Semana do Meio Ambiente para realizar vivências socioambientais. Esta situação possibilitou abordar questões de cunho ecológico, relativas à qualidade de vida, bem como o contexto legal de proteção às nascentes.

Os sujeitos que vivenciam este tipo de ação passam a conhecer melhor os processos de melhoria ambiental e como são feitas as intervenções, dimensionando também seu custo financeiro. Essas vivências possibilitam o acesso a elementos para uma progressiva geração de consciência que possa resultar em escolhas éticas. Na maioria das vezes, esses indivíduos tornam-se multiplicadores dessas ações, uma vez que se observou a replicação, em especial no caso da proteção de nascentes e córregos.

As práticas em EA ajudam a comunidade a compreender que a educação pode constituir espaço privilegiado de construção de conhecimentos sobre o que se produz na interação homem-sociedade-natureza, e, assim, criar condições para novas relações. Cabe reconhecer, entretanto, que as ações desenvolvidas como práticas de EA na escola de campo não se distanciam substancialmente do conceito de educação conservadora, conforme Loureiro (2003), que ensina que o problema principal a ser enfrentado em grande medida acaba, intencionalmente ou não, reproduzindo um modelo que não enfrenta a relação produção-consumo-cultura, restringindo-se a práticas rotineiras de EA, a exemplo da reciclagem.

Nunca é demais ressaltar, portanto, que a ação transformadora da educação possui limites, ou seja, não é suficiente em si realizar uma práxis educativa cidadã, participativa e revolucionária, se isso não se relacionar diretamente com outras esferas da vida. Nesse sentido, o mérito das ações, propostas no presente trabalho, foi de fortalecer os vínculos afetivos entre os educandos, educadores e a comunidade, sem os quais o resultado do trabalho é muito restrito e foge aos pressupostos de uma verdadeira EA transformadora. 
Em uma pesquisa sobre a EA do ponto de vista das concepções de desenvolvimento sustentável na escola do campo, Mallman, Carniatto e Plein (2020, p. 28) concluem:

\begin{abstract}
...ao se instigar a curiosidade pelo mundo e realidade alheia é possível elaborar diferentes estratégias, que passam a ser adaptadas para sua realidade de forma que aconteça a "reinvenção" do conhecimento trazido pelo educador. Resulta dessa ação o sujeito que se compreende inserido num contexto e capaz de agir conscientemente na transformação do mundo.
\end{abstract}

Conforme Guimarães (2000), em uma concepção crítica de EA acredita-se que a transformação de cada indivíduo resulta da reciprocidade dos processos nos quais é propiciada a transformação de ambos. Nesta visão, educando e educador são agentes sociais que atuam no processo de transformações sociais; portanto o ensino é teoria/prática, é práxis; ensino que se abre para a comunidade com seus problemas sociais e ambientais, sendo estes conteúdo do trabalho pedagógico. Aqui, a compreensão e a atuação sobre as relações de poder que permeiam a sociedade podem emergir, constituindo uma educação política. Em cada ação singular de EA, portanto, é necessário ter sempre presente que

O ambiente não é ecologia, mas a complexidade do mundo; é um saber sobre as formas de apropriação do mundo e da natureza através das relações de poder que se inscreveram nas formas dominantes de conhecimento (LEFF, 2001, p. 17).

\title{
Conclusões
}

A Educação Ambiental nas escolas de campo precisa ser um processo contínuo e permanente e pode constituir-se em um caminho para a conquista de uma sociedade sustentável. Deve, entretanto, diferenciar-se quanto à abordagem, apoiando-se em uma práxis que vincule educandos, educadores e comunidade e estabeleça o nexo entre a vivência educacional e a vida do campo. Trata-se de um desafio permanente de exercício de criatividade e sensibilidade para construir espaços e oportunidades de crescimento mútuo entre discentes, docentes e comunidade. A escola é um dos espaços de aprendizagem, local de se estabelecer relações significativas entre o novo e o que já se conhece, levando em conta a dimensão afetiva e social.

Práticas em que a relação entre educação e ambiente são, por vezes, consideradas reducionistas, ou meramente pontuais, como as apresentadas no presente trabalho, podem ser ressignificadas com a construção de uma percepção mais ampla, aprofundada e crítica da EA. Essas práticas são essencialmente espaços de convivência que representam uma qualificada 
oportunidade, desde que os educadores assumam uma educação transformadora pautada na práxis.

Embora haja o reconhecimento que ações, por vezes pontuais, possam estar alinhadas a uma educação considerada conservadora, acredita-se que elas possam se constituir nos primeiros degraus de aprendizagem coletiva e, progressivamente, avançar para uma prática que contribua para a transformação pedagógica e, de certa forma, para a social. Temas recorrentes de EA, como hortas escolares, reciclagem e plantio de árvores, têm o potencial de, progressivamente, incorporar outras dimensões da relação sociedadenatureza e avançar na constituição de uma EA plena e transformadora.

As práticas em EA ajudam a comunidade a compreender que a Educação Ambiental pode constituir espaço privilegiado de construção de conhecimentos sobre a relação da interação homem-sociedade-natureza, e, assim, criar condições para novas relações na sociedade, que resultem numa comunhão com o ambiente.

Em uma concepção crítica de EA, acredita-se que a transformação de cada indivíduo resulta da reciprocidade dos processos nos quais é propiciada a transformação de ambos.

\section{Referências}

BARBIERI, J. C.; SILVA D. da. Desenvolvimento sustentável e Educação Ambiental: uma trajetória comum com muitos desafios. RAM, Rev. Adm. Mackenzie, v. 12, n. 3, p. 51-82, jun. 2011.

BAROLDI, C.; LOPES, M. M. A Educação Ambiental como ferramenta para construção de espaços educadores sustentáveis. Revista Gestão Universitária, jul. $2017 . \quad$ Disponível em: $<$ www.gestaouniversitaria.com.br/artigos/a-educacao-ambiental-comoferramenta-para-construcao-de-espacos-educadores-sustentaveis>. Acesso em: 14 out. 2019.

BOFF, L. Saber cuidar: ética do humano - compaixão pela terra. 2. ed. Petrópolis: Vozes, 1999.

BRASIL. Ministério da Educação e Cultura. Diretrizes operacionais para a Educação Básica das Escolas do Campo. Brasília: CNE; MEC, 2002.

BRASIL. Diário Oficial da União. Lei no 9.795 de 27 de abril de 1999. Dispõe sobre a Educação Ambiental, institui a Política Nacional de Educação Ambiental e dá outras providências. Brasília, DF. Disponível em: $<$ https://mma.gov.br/educacao-ambiental/pol\%C3\%ADtica-nacional-deeduca\%C3\%A7\%C3\%A3o-ambiental.html>. Acesso em: 15 set. 2019.

CAPRA, F. et al. Alfabetização ecológica: a educação das crianças para um mundo sustentável. São Paulo: Cultrix, 2006. 
CARDONA, B. N. H. L.; BARRETO, M. M. A construção de horta suspensa como alternativa à degradação dos solos na agricultura urbana. 2014. $19 \mathrm{f}$. Trabalho de Conclusão de Curso (Licenciatura em Ciências Biológicas) Faculdade de Ciências e da Educação em Saúde, Centro Universitário de Brasília, Brasília, 2014.

CARVALHO, I. A invenção ecológica: narrativas e trajetórias da Educação Ambiental no Brasil. Porto Alegre: Editora da UFRGS, 2001.

COSTA, C. A. G. da; SOUZA, J. T. A.; PEREIRA, D. D. Horta escolar: alternativa para promover Educação Ambiental e desenvolvimento sustentável no Cariri paraibano. Polêmica, v. 15, n. 3, p. 1-9, 2015.

GUIMARÃES, M. A formação de educadores ambientais. Campinas: Papirus, 2004.

GUIMARÃES, M. Educação Ambiental: no consenso um embate? 5. ed. Campinas: Papirus, 2000.

JACOBI, P. R. Environmental education: the challenge of constructing a critical, complex and reflective thinking. Educação Pesquisa, São Paulo, v. 31, n. 2, p. 233-250, Aug. 2005.

JACOBI, P. R. Educação e meio ambiente: transformando as práticas. Rede Brasileira de Educação Ambiental, Brasília, n. 0, p. 28-35, 2004.

KONDER, L. O futuro da filosofia da práxis. 2. ed. Rio de Janeiro: Paz e Terra, 1992.

LEFF, E. Epistemologia ambiental. São Paulo: Cortez, 2001.

LEFF, E. Saber ambiental. Petrópolis: Vozes, 2002. 343 p.

LEFF, E. Saber ambiental: sustentabilidade, racionalidade, complexidade e poder. 9. ed. Petrópolis: Ed. Vozes, 2012.

LIMA, G. F. C. Educação Ambiental crítica: do socioambientalismo às sociedades sustentáveis. Educação e Pesquisa, São Paulo, v. 35, n. 1, p. 145-163, jan./abr. 2009.

LOUREIRO, C. F. B. Premissas teóricas para uma Educação Ambiental transformadora. Ambiente e Educação, Rio Grande, n. 8, p. 37-54, 2003.

LUCENA, T. C. de; FIGUEROA, M. E. V.; OLIVEIRA, J. C. A. de. Educação Ambiental, sustentabilidade e saúde na criação de uma horta escolar: melhorando a qualidade de vida e fortalecendo o conhecimento. Revista Brasileira de Educação e Saúde, v. 5, n. 1, p. 1-9, 2015.

LÜDKE, M.; ANDRÉ, M. E. D. A. Pesquisa em educação - abordagens qualitativas. São Paulo: EDU, 1986.

MALLMAN, A.; CARNIATTO, I.; PLEIN, C. A Educação Ambiental do ponto de vista das concepções de desenvolvimento sustentável na escola do campo. Revista Brasileira de Educação Ambiental, São Paulo, v. 15, n. 1, p. 44-61, 2020.

Revbea, São Paulo, v.16, № 1: 114-129, 2021. 
MEINARDI, E.; REVEL CHION, A.; GONZALES URDA, E. (colab.). Teoría y Práctica de la educación Ambiental. 1. ed. Buenos Aires: Aique Grupo Editor, 1997.

MORIN, E. Complexidade e transdisciplinaridade: a reforma da universidade e do Ensino Fundamental. Natal: Editora da UFRN, 2000.

MORIN, E. Ciência com consciência. Rio de Janeiro: Bertrand Brasil, 2002.

MORIN, E. et al. Educar na era planetária. São Paulo: Cortez, 2003.

ONU. Organizações das Nações Unidas. A Agenda 2030. 2015. Disponível em https://nacoesunidas.org/pos2015/agenda2030/. Acesso em: 15 set. 2019.

PEREIRA, B. F. P.; PEREIRA, M. B. P.; PEREIRA, F. A. A. Horta escolar: enriquecendo o ambiente estudantil Distrito de Mosqueiro-Belém/PA. Revista Brasileira de Educação Ambiental, Rio Grande, v. 7, p. 29-36, 2012.

RODRIGUES, A. P. S.; KINDEL, E. A. I. Separação de resíduos e horta como ferramentas de transformação do espaço escolar. Rev. Eletrônica Mestr. Educ. Ambiente, Rio Grande, v. 36, n. 1, p. 221-241, jan./abr. 2019.

RODRIGUES, G. S. de S. C.; COLESANTI, M. T. de M. Educação Ambiental e as novas tecnologias de informação e comunicação. Sociedade \& Natureza, Uberlândia, v. 20, n. 1, p. 51-66, jun. 2008.

SILVA, L. F. Educação Ambiental crítica: entre ecoar e recriar. 2009. 197 f. Tese (Doutorado) Programa de Pós-graduação em Educação. Faculdade de Educação - Universidade de São Paulo. 2009.

TRISTÃO, M. Saberes e fazeres da Educação Ambiental no cotidiano escolar. Revista Brasileira de Educação Ambiental, Brasília: Rede Brasileira de Educação Ambiental, n. 0, p. 47-55, nov. 2004.

ZANELLI, J. C. Pesquisa qualitativa em estudos da gestão de pessoas. Estudos da Psicologia, n. 7, p. 79-88, 2002. 